\title{
A Family with Two Translocations and a Polymorphism Involving Chromosome 14
}

\author{
PATRICIA A. JACOBS,* KARIN E. BUCKTON, SHEILA CHRISTIE, \\ MARJORIE NEWTON, and DOUGLAS MATTHEW

\section{Medical Research Council, Clinical and Population Cytogenetics Unit Western General Hospital and Infertility Clinic, Royal Infirmary, Edinburgh}

We wish to report the study of a family in which cytogenetic investigations showed the presence of two translocations and a polymorphism all of which involved chromosome 14.

The family (K138, Fig. 1) was ascertained through

Received 10 September 1973.

* Present address: Department of Anatomy and Reproductive Biology, University of Hawaii School of Medicine, Honolulu, Hawaii 96822, USA. a couple who presented at a sub-fertility clinic with a history of two spontaneous abortions and no live born children after three years of marriage. Examination revealed a healthy 23-year-old female and a 27-year-old male, neither of whom had any previous relevant medical history. In addition to the two original spontaneous abortions, at 8 and 10 weeks respectively, the couple had a subsequent

\section{KEY}

$Q^{7}$ Dead-inferred carrier

Ф Chromosomes normal

(1) $t(6 p 14 p ; 6 q 14 q)$

(11) $15 \mathrm{ps}+$

$14 \mathrm{ph}+$

$t(14 q 15 q)$

Spontaneous abortion

Proband
K138

I

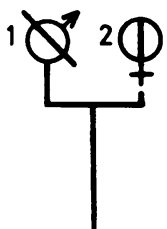

II

III

IV
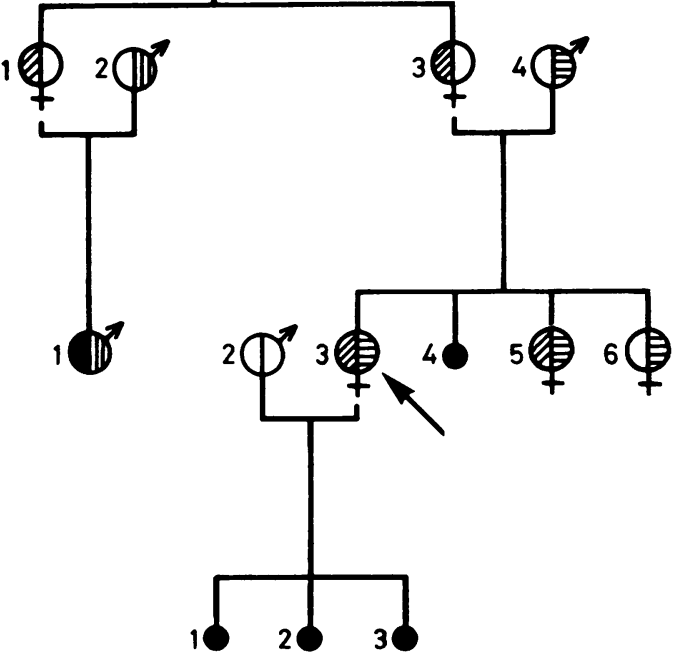

FIG. 1. Pedigree of the family. 
third abortion at 21-weeks' gestation, which was an anencephalic fetus. Clinical investigations revealed no cause for the recurrent abortions.

Chromosome studies of cultured peripheral blood leucocytes stained by the Acetic-Saline-Giemsa (ASG) technique (Sumner, Evans, and Buckland, 1971) showed the husband (III.2) to have a $46, X Y$ constitution and the wife (III.3) to have a reciprocal translocation between a chromosome 6 and a chromosome 14 and to have, in addition, long short arms on the chromosome 14 not involved in the translocation. Her chromosome constitution was $46, \mathrm{XX}, 14 \mathrm{ph}+, \mathrm{t}(6 \mathrm{p} 14 \mathrm{p} ; 6 \mathrm{q} 14 \mathrm{q})$. Cytogenetic investigations were undertaken on the available relatives of III.3 all of whom were clinically unremarkable (Fig. 2). One of her sisters (III.5) was found to have both the $t(6 ; 14)$ and the $14 \mathrm{ph}+$, while the other sister (III.6) did not carry the translocation but did have the $14 \mathrm{ph}+$. The proposita's mother (II.3) and maternal aunt (II.1) were both found to be carriers of the $t(6 ; 14)$ while the father (II.4) had the $14 \mathrm{ph}+$. The maternal grandmother (I.2) had a normal chromosome constitution and, while the maternal grandfather (I.1) was dead, it could be inferred that he carried the translocation because he had two affected children. The only other relative available for study was a clinically un- remarkable unmarried 26-year-old male (III.1), $\Omega$ the only child of the proposita's maternal aunt. He was found to be the carrier of a Robertsonian translocation between a chromosome 14 and a chromo- $\vec{F}$ some 15 , having a $45, \mathrm{XY}, \mathrm{t}(14 \mathrm{q} 15 \mathrm{q})$ constitution. As his father (II.2) had a $46, \mathrm{XY}$ constitution the son must be the result of a mutational event which presumably occurred in a germ cell of one or other of his parents.

In an attempt to determine the parental chro- है mosomes involved in the translocation we looked for cytogenetic polymorphisms in parents and son, utilizing the centromeric heterochromatin (Sumner, 1972) and quinacrine fluorescence techniques (O'Riordan et al, 1971). In the event, the Qbanding technique proved particularly informative (Fig. 3). The father was found to have a chromosome 15 with double satellites, the proximal ones being brightly fluorescing and the distal ones palely fluorescing. This chromosome was also present in his son, as the free chromosome 15. We can say therefore that, because the son has inherited his non-translocated chromosome 15 from his father, his $14 \mathrm{q} 15 \mathrm{q}$ translocation must be maternal in origin. Unfortunately, because of the absence of suitable polymorphisms, it was not possible to determine whether the free or the translocated

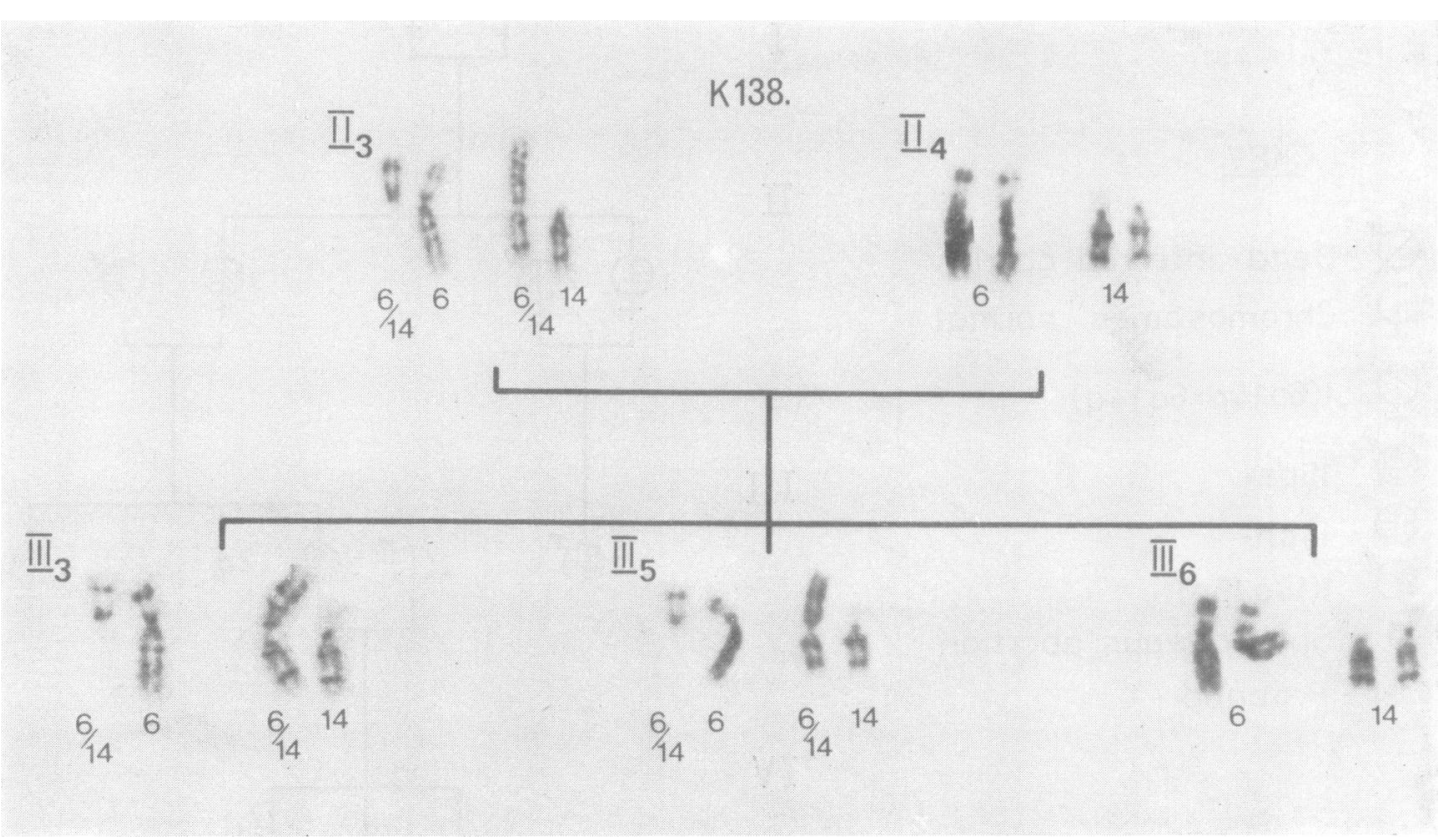

FIG. 2. Chromosomes No. 6 and No. 14 from the proposita, her sibs and parents. (ASG stain.) 


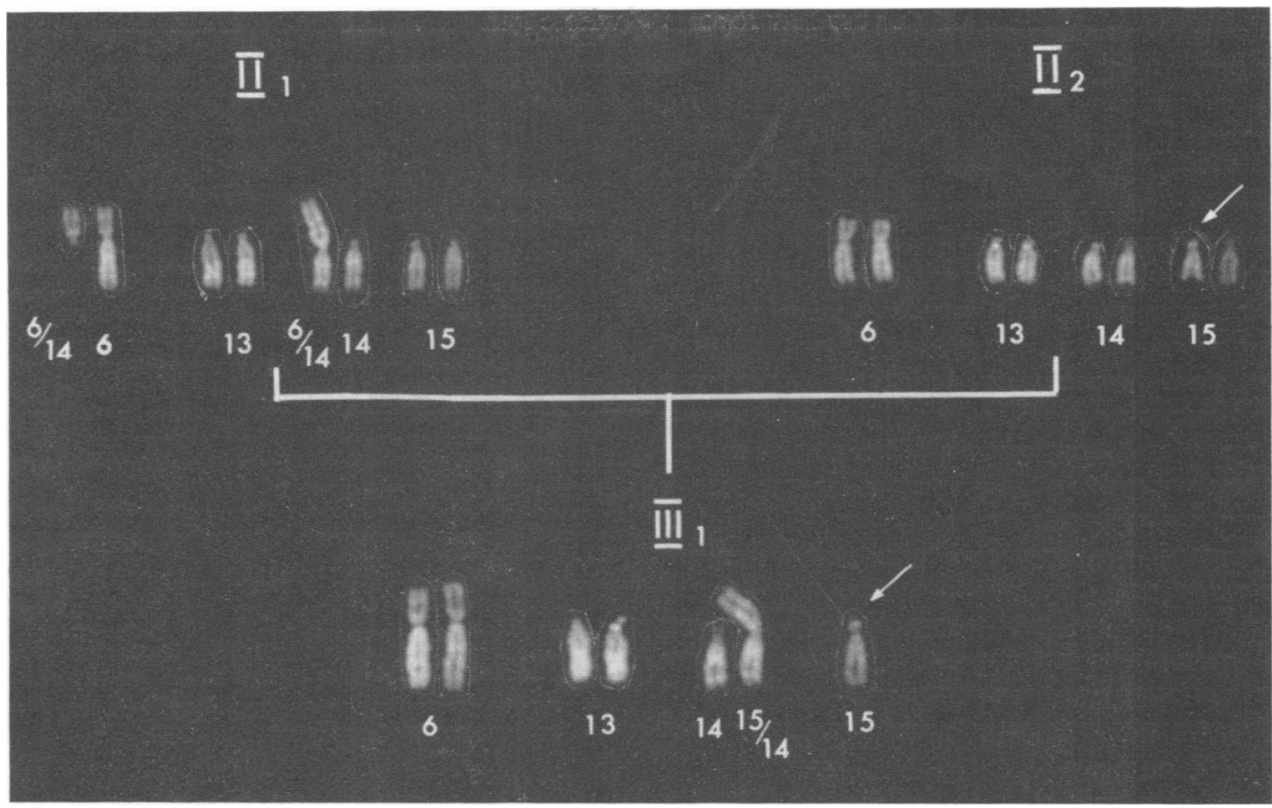

FIG. 3. Chromosomes No. 6, 13, 14, and 15 from III.1 with $\mathrm{t}(14 \mathrm{q} 15 \mathrm{q})$ and his parents. (Quinacrine dihydrochloride stain.)

maternal chromosome 14 was the one involved in the $14 \mathrm{q} 15 \mathrm{q}$ translocation in the son.

\section{Discussion}

The observations in this family raise two questions. Firstly, is the translocation $(6 \mathrm{p} 14 \mathrm{p} ; 6 \mathrm{q} 14 \mathrm{q})$ relevant to the proposita's subfertility and second, is the mutation in the germ cells of the proposita's aunt a chance occurrence or is it related to her translocation? Unfortunately no clear answer can be given to either question.

While the proposita has produced no live born children, three other carriers of the same translocation (I.1, II.1, and II.3) have had seven recorded pregnancies of which only one (III.4) terminated as a spontaneous abortion during the 6th week of gestation. Thus the presence of this translocation is compatible with a normal reproductive history, although it may be a contributing factor to the proposita's sub-fertility.

Euploid Robertsonian translocations involving two D-group chromosomes are one of the commonest autosome structural rearrangements in man, occurring with a frequency of 0.01 to $0.05 \%$ (Jacobs et al, 1974). However the great majority of these involve chromosomes 13 and 14 and translocations of the $14 \mathrm{q} 15 \mathrm{q}$ and $13 \mathrm{q} 15 \mathrm{q}$ type are rare (Cohen, 1971; Jacobs et al, 1974). Furthermore only some $5-10^{\circ}$ of propositi with a euploid $\mathrm{D} / \mathrm{D}$ Robertsonian translocation are found to be mutants. The combined mutation rate for all euploid Robertsonian translocations of the $\mathrm{D} / \mathrm{D}$ class must therefore be of the order of $2.5 \times 10^{-5}$ per gamete per generation. The proportion of these mutations which occur between a No. 14 and a No. 15 is unlikely to be more than a third of the total and may well be considerably less than this. Therefore the frequency of gametes which effect fertilization and which are mutant for a $14 \mathrm{q} 15 \mathrm{q}$ translocation is $\leqslant 8 \times 10^{-6}$. Thus, on the null hypothesis that the translocations in II.1 and III.1 are independent events, we can say that the probability of II.1 having a fertilized gamete which is a mutant for a $14 \mathrm{q} 15 \mathrm{q}$ translocation is equal to the gametic frequency of $\leqslant 8 \times 10^{-6}$ per gamete per generation.

Clearly, in a single case it is impossible to choose between a chance association and a cause and effect relationship for the two translocations. However, in the present family it is tempting to favour the latter because (1) we know the mutation occurred in the parent who already carried a chromosome rearrangement; (2) a chromosome number 14 is involved in both translocations, and (3) both translocations are whole arm exchanges and therefore chromosome 14 must be broken at or near the centromere in both rearrangements. 
We have been able to find only a very few reports in the literature of mutant structural aberrations occurring in the offspring of parents, one of whom has a different structural abnormality. Thomas and Bias (1970) reported a de novo $\mathrm{t}(\mathrm{Bp}+; \mathrm{Cp}-)$ whose father had a normal constitution and whose mother had a $t(\mathrm{DqGq})$ constitution, while Marsden et al (1966) described a G/G translocation Down's syndrome child who also had inherited a $D / D$ translocation from his mother, the father's chromosomes being normal. These cases differ from the one reported here in that the two translocations do not have any chromosomes in common and because the identity of the parental gamete which contributed the mutation is not known.

If one structural abnormality of the chromosomes does influence the production of others, the effect could be restricted to the chromosomes involved in the primary rearrangement, or it might affect both the chromosomes involved and their homologues, or it could be more general and affect the whole genome. However, more data are required before the nature of any such effect can be established.

\section{REFBRENCES}

Cohen, M. M (1971). The chromosomal constitution of 165 human translocations involving D group chromosomes identified by autoradiography. Annales de Génétique, 14, 87-96.

Jacobs, P. A., Buckton, K. E., Cunningham, C., and Newton, M. (1974). An analysis of the break points of structural rearrangements in man. Fournal of Medical Genetics, 11, 50-64.

Marsden, H. B., Mackay, R. I., Murray, A., and Ward, H. E. (1966). Down's syndrome with a familial $D / D$ reciprocal translocation and a G/G chromosome. Fournal of Medical Genetics, 3, 56-58.

O'Riordan, M. L., Robinson, J. A., Buckton, K. E., and Evans, H. J. (1971). Distinguishing between the chromosomes involved in Down's syndrome (Trisomy 21 ) and chronic leukaemia $\left(\mathrm{Ph}^{1}\right)$ by fluorescence. Nature, 230, 167-168.

Sumner, A. T. (1972). A simple technique for demonstrating centromeric heterochromatin. Experimental Cell Research, 75, 304306.

Sumner, A. T., Evans, H. J., and Buckland, R. A. (1971). New technique for distinguishing between human chromosomes. Nature New Biology, 232, 31-32.

Thomas, G. H. and Bias, W. B. (1969). Occurrence of a presump- 응 tive $\mathrm{C} / \mathrm{B}$ translocation carrier $(46, \mathrm{XY}, \mathrm{t}(\mathrm{Cp}-; \mathrm{Bp}+))$ in a family of $\mathrm{D} / \mathrm{G}$ translocation carriers $(45, \mathrm{D}-, \mathrm{G}-, \mathrm{t}(\mathrm{DqGq})+$ ). Fournal of Medical Genetics, 6, 382-387. 